\title{
CAN A RADIO SERIES GHANGE ATTITUDES AND NORMS ON VIOLENGE AGAINST WOMEN?
}

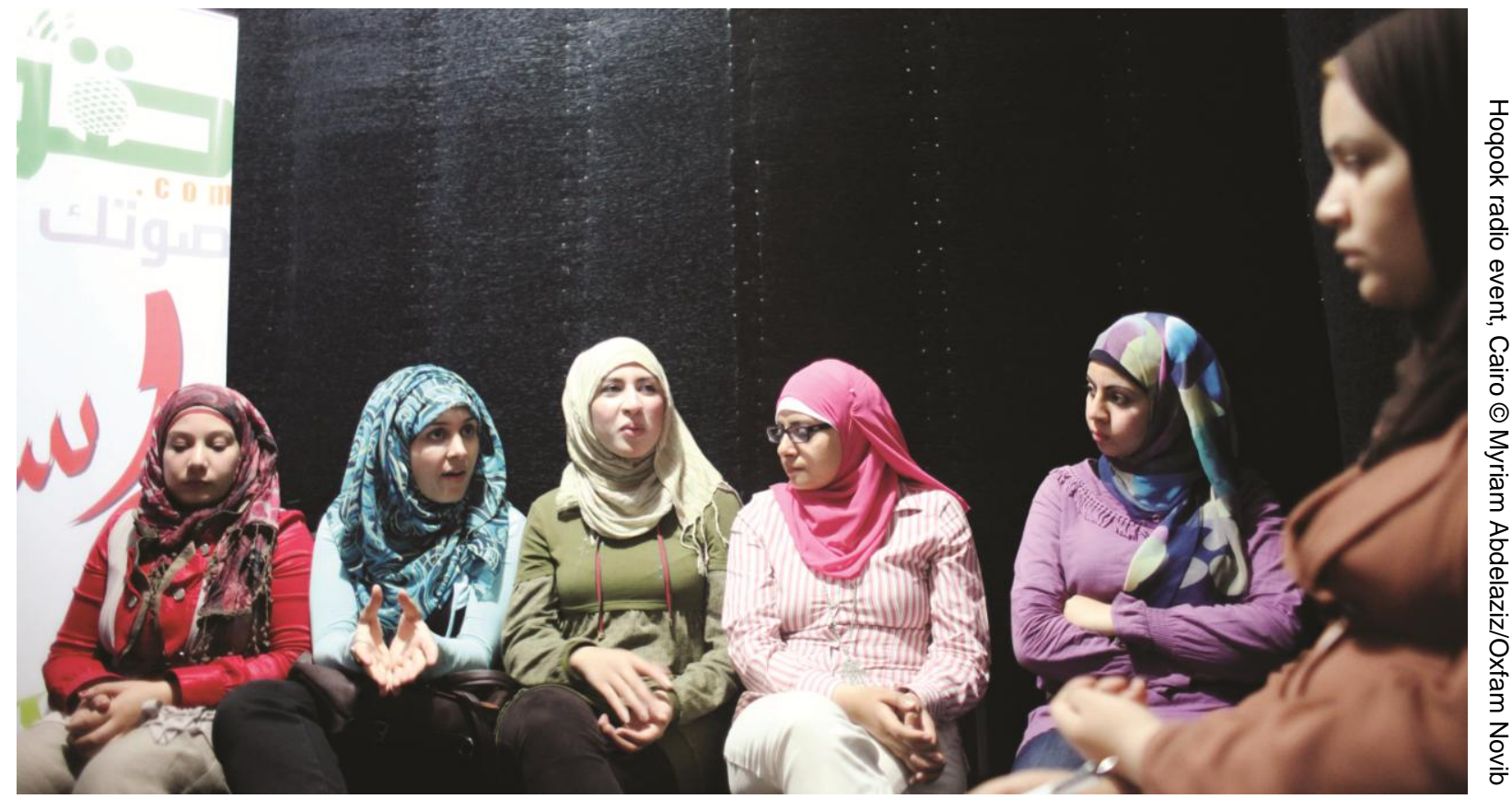

\section{SUMMARY}

- Evidence suggests edutainment can increase awareness, change attitudes, and motivate action in regard to violence against women and girls

$>$ These changes are likely produced when a program's listeners actively participate in discussions after an edutainment series, rather than exposure to the series alone

$>$ Self-confidence-an important attribute for listeners to effectively engage in discussions-is also produced through participation in the project and seems to lead to increased motivation to change

\section{EDUTAINMENT AND EVIDENCE}

Edutainment is the combination of entertainmentoften television or radio soap operas-with educational messages that aim to mobilise and promote positive changes in attitudes, behaviours and social norms. According to the World Bank's 2015 Development Report, edutainment has the potential to achieve large-scale behaviour change, and many other studies have noted similarly positive results. However, rigorously-gathered evidence of edutainment's impact on behaviour change is still lacking. Oxfam has implemented edutainment programmes in 14 countries and is constantly seeking to better understand its impact. In 2015, Oxfam's impact measurement unit conducted a rigorous (randomised) evaluation of an edutainment pilot project in Tunisia. 


\section{THE INTERVENTION}

In Tunisia, almost half of all women have experienced at least one form of violence in their lifetime, including more than $40 \%$ experiencing physical violence and $75.4 \%$ experiencing harassment in the public space. Oxfam's edutainment intervention was part of Oxfam in Tunisia's work to eliminate violence against women and girls (VAWG), which aims to enhance knowledge, promote positive attitudes towards gender equality, and challenge norms that make VAWG in Tunisia socially acceptable.

Participants in Oxfam's edutainment project were organised into groups to listen to an Egyptian edutainment radio series, "Worth 100 Men," a production of the Womanity Foundation, followed by a facilitated debate on each episode's themes. The series stars popular actress Mona Zaki as a journalist named Noha. Noha serves as a positive role model, tackling issues such as sexual harassment, violent relationships, sexism, and corruption.

\section{THE EVALUATION}

The pilot and impact assessment aimed to investigate whether active participation in listening groups and debates could successfully increase knowledge and change attitudes and perceptions of social norms with regards to women's empowerment and VAWG in Tunisia. Oxfam and Tunisian partners identified over 300 potential project participants within their local communities, who were randomized into target and control groups. A baseline and endline survey was conducted with all groups and the quantitative data was supplemented by the collection of 20 in-depth interviews using the "Most Significant Change" methodology'.

\section{IMPACT}

The evaluation finds evidence of impact on:

- Awareness of violence against women: following the series, participants were more likely to report personally knowing someone who had suffered from violence.

- Attitudes about violence against women: after having listened to the series, participants were less likely to justify violence against women.

- Intention to take action on violence against women: following the series participants were more likely to intend to advise others who suffer from violence to speak out.
There was no difference in the impact between men and women.

\section{AWARENESS OF VIOLENCE AGAINST}

\section{WOMEN IN DIRECT SURROUNDINGS}

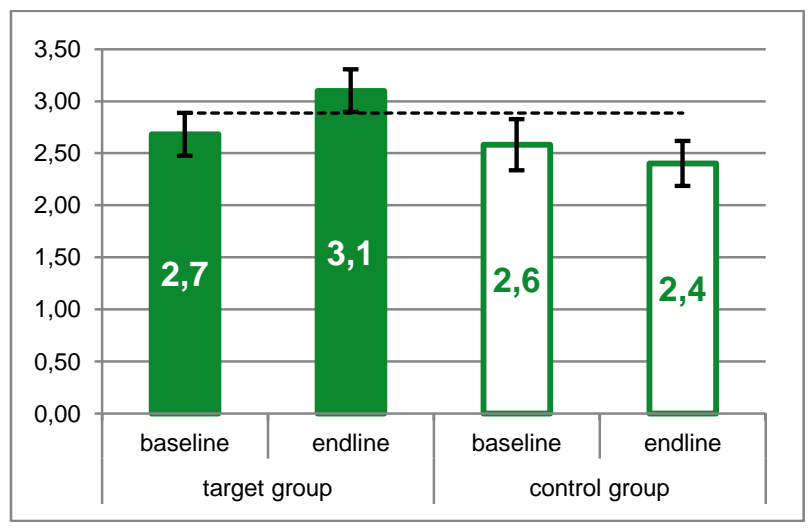

Scale value ${ }^{\mathrm{ii}}$, difference between baseline and endline for target and control group. Target: statistically significant difference $(p<0,01)$; Control: difference is not statistically significant.

\section{JUSTIFICATION OF VIOLENCE AGAINST}

\section{WOMEN IN INTIMATE RELATIONSHIPS}

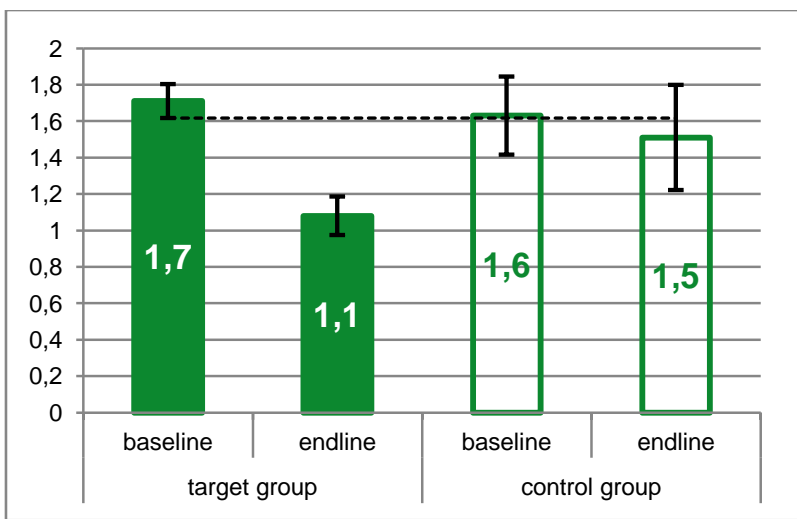

Scale value ${ }^{\mathrm{iii}}$, difference between baseline and endline for target and control group. Target: statistically significant difference $(p<0,01)$; Control: difference is not statistically significant.

\section{ADVISING OTHERS TO TAKE ACTION ON VIOLENCE AGAINST WOMEN}

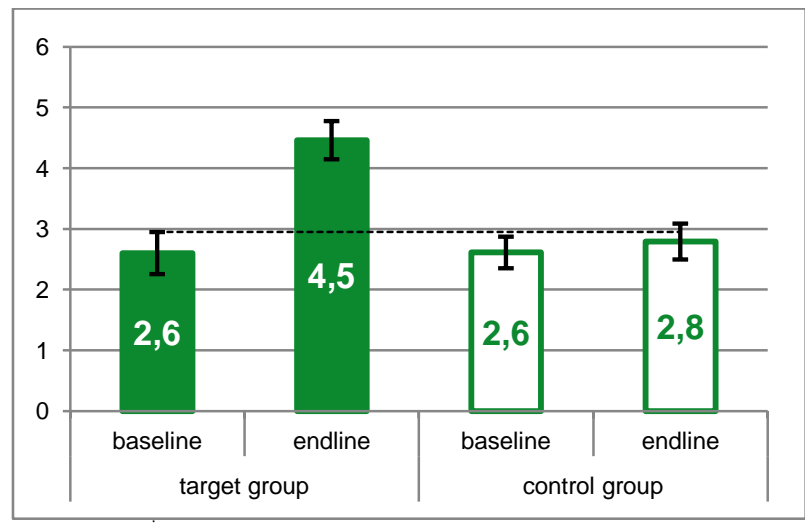

Scale value ${ }^{\text {iv }}$, difference between baseline and endline for target and control group. Target: statistically significant difference $(p<0,01)$; Control: difference is not statistically significant. 
No significant impact was found on attitudes that justify women staying in violent relationships, changes in perceptions of social norms (such as how participants think others in their community perceive violent relationships), or the way participants view the role of women in society.

"I began to pay more attention to issues of women, particularly different forms of violence against women in all areas of life". Project participant, Tunis.

Survey results showed that both men and women liked the series, and liked the discussions even more. Evidence from the in-depth interviews indicates that impact is likely produced through engaging in the discussions rather than exposure to the series alone. This indicates that scale-up of edutainment programming should not focus exclusively on national broadcasts but also on social mobilisation.

\section{"If I didn't meet you and attend the sessions,}

\section{I wouldn't be able to express myself}

in such a confident way." Project participant, Jendouba.

Qualitative data indicates an important mechanism for achieving change is increasing self-confidence and providing motivation to discuss and have an opinion on issues. This is achieved through participation in the debate on the themes of the series. Facilitators of listening sessions should therefore first work on building self-confidence amongst participants to enable them to participate fully in the debates. In-depth interviews also showed that participants who felt more confident were likely to discuss the issues with friends and family, which indicates potential for spill-over effects.

"I've become responsible for myself, capable to claim my rights with courage". Project participant, Tunis.

While Egyptian films and soap operas are widely shown in Tunisia, the differences in dialect and context had the potential to reduce the impact of the series. There was evidence, however, that despite the Egyptian dialect and context of the series, many listeners in Tunisia liked the character of Noha, identified with her and used her experiences to make up their own minds on specific issues, showing that impact can be achieved even with a non-contextualised series.
IDENTIFICATION WITH MAIN CHARACTER

\section{\% AGREE/COMPLETELY AGREE}

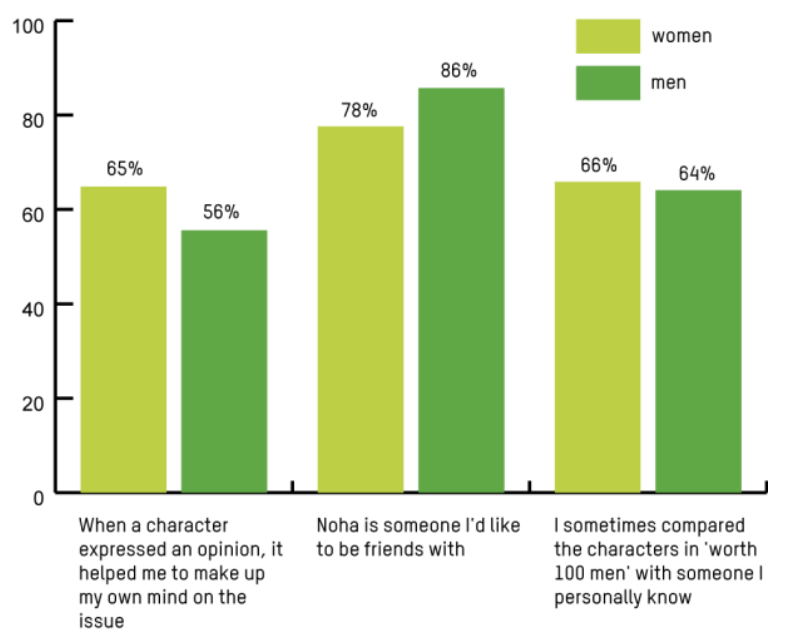

Savings could be made by using the same Arabic language products throughout the region, but more impact could potentially be achieved with local production and contextualisation.

"Noha is an example of a well-informed woman with a good education and a strong personality. Had she been a real person I would have wanted her to be my sister." Project participant, Tunis.

\section{WANT TO KNOW MORE?}

Contactworldcitizenspanel@oxfamnovib.nl

Scan this code to listen to episodes of the Worth 100 Men radio series (in Arabic)

Starring: Mona Zaki, Khaled Eleish \& Nancy Ajram

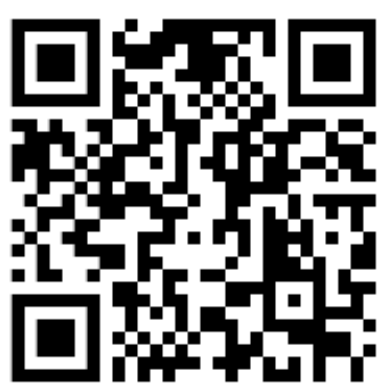


${ }^{\mathrm{i}}$ Oxfam uses an adapted version of the Most Significant Change methodology to accompany quantitative data in many of its impact assessments. The methodology invites project participants to reflect on changes that have happened in their lives since participating in the project, and to identify and recount in detail the change which was the most significant for them, in order to provide more information on the drivers of this change.

ii Items in questionnaire $(n=389)$ : In the past 12 months, do you think these things have happened to women close to you? Answer yes (1) or no (0) to the following questions: Someone has: Insulted/humiliated her or made her feel bad about herself?; Threatened to hurt her or to hurt someone she cares about?; Hit her or tried to hit her with anything?; Actually inflicted serious damage to one or more parts of her body?; Forced her to have sex even when she did not want to?

iii Items in questionnaire: Sometimes men are violent towards their wife or fiancée. Please tell me whether you find violent behaviour justified in the following situations. Answer on a 5point Likert scale ("never justified" $=0$ to "always justified" $=5$ ) to the following questions: Wife does not complete housework or prepare the food properly; For any reason at all, if he wants to; Wife goes out without telling him; Wife refuses to have sex with him; Wife is unfaithful; Wife argues with him.

iv Items in questionnaire: I would advise my friend or relative to speak out or take action if her partner.... Number of times answered 'yes' on the following questions: Range: minimum 1 maximum 5: Threatened to hurt her physically; Tries to keep her from seeing friends, family or relatives; Belittled her in front of other people; Pushed her or shoved her; Beat her or kicked her

\section{Oxfam Novib juni 2016}

This document was written by Caroline Hodges.

For more information or to comment on this publication, please email

Caroline.hodges@oxfamnovib.nl.

This publication is copyright but the text may be used free of charge for the purposes of advocacy, campaigning, education, and research, provided that the source is acknowledged in full. The copyright holder requests that all such use be registered with them for impact assessment purposes. For copying in any other circumstances, or for re-use in other publications, or for translation or adaptation, permission must be secured and a fee may be charged. E-mail Caroline.hodges@oxfamnovib.nl for more information.

Image credit

Cover photo (c) Myriam Abdelaziz/Oxfam Novib

Published by Oxfam Novib in May 2016.

Oxfam Novib

P.O. Box 30919

$2500 \mathrm{GX}$ The Hague

The Netherlands

$\mathrm{T}+31(0) 703421621$

info@oxfamnovib.nl

www.oxfamnovib.nl 